\title{
Téoros
}

Revue de recherche en tourisme

\section{Le marché américain}

\section{Pierre Bellerose}

Volume 9, numéro 2, juillet 1990

Le marché américain

URI : https://id.erudit.org/iderudit/1080023ar

DOI : https://doi.org/10.7202/1080023ar

Aller au sommaire du numéro

Éditeur(s)

Université du Québec à Montréal

ISSN

0712-8657 (imprimé)

1923-2705 (numérique)

Découvrir la revue

Citer ce document

Bellerose, P. (1990). Le marché américain. Téoros, 9(2), 2-2.

https://doi.org/10.7202/1080023ar d'utilisation que vous pouvez consulter en ligne.

https://apropos.erudit.org/fr/usagers/politique-dutilisation/ 


\title{
Présentation
}

\author{
Pierre Bellerose
}

\section{Le marché américain}

Projet fort ambitieux que celui de réaliser un numéro de Téoros sur un theme aussi vaste, complexe et mouvant que le marché américain. Loin de nous la prétention de vouloir cerner complètement le sujet. Nous espérons plutót fournir aux lecteurs certaines avenues de réflexion et ainsiamener une meilleure compréhension de ce marché incontournable pour l'intervenant touristique, peu importe son champ et territoire d'action. Le tourisme américain (qu'il soit d'agrément ou autre) a trop longtemps été perçu comme étant monolithique et sans nuance. Le présent numéro s'attarde précisément à briser cette image et à en souligner les multiples facettes.

Deux auteurs analysent les changements en profondeur que vit actuellement ce marché américain et cela à de multiples niveaux. Jean-Marc Bissonnette étudie les transformations en cours du mode de vie des Américains et leurs impacts sur les voyages dans les prochaines années. Son interprétation de la tendance au "repli sur soi" est, en ce sens, très évocatrice. De son cóté, David Redekop insiste sur les nouvelles niches (et opportunités) de marché que sont les communautés ethniques grandissantes - hispaniques, noires et asiatiques.

Elizabeth Stewart a le merite de remettre les choses en perspective dans son article surle tourisme des Américains aux Etats-Unisen démontrant que ceux-cipréfèrent voyager chez eux. Cependant, le texte que j'ai fait a partir des résultats de la deuxième édition de l'Enquête Longwoods montre que cette habitude de voyager principalement aux Etats-Unis n'est pas synonyme de fermeture puisque la perception du Canada est meilleure que celle de leur propre pays.

Patrick Cluzeau fait une importante analyse des voyages des Américains au Québec depuis une quinzaine d"années et souligne la décroissance de ce marché au Québec entre 1972 et 1989.

L'article quej'aiécrit sur les voyages-motivationm'a permis de démontrer l'importance de ce segment de marché méconnu ici mais combien important aux Etats-Unis. II s'agit en fait du segment avec la plus forte croissance de tous les secteurs touristiques aux États-Unis.

Cependant, d'autres éléments fondamentaux influent directement sur ces touristes américains et se devaient d'être analysés dans le cadre de ce numéro. Ainsi, Jean Pelletier scrute les effets de la déréglementation du transport aérien aux États-Unis et montre que les impacts n'ont peut - tre pas été à la mesure des attentes. Pauline Sheldon, dans un texte fouillé et important, analyse l'état actuel du réseau de distribution aux États-Unis et fait ressortir, entreautres, l'effetde l'implantationdes nouvelles technologies. Finalement, Barbara Di Stephano présente la stratégie marketing de Tourisme Québec sur le marché américain.

Le marché américain constitue la plus importante opportunité touristique pour le Québec et pour la planète d'icil'an 2000. Cependant, le pluralisme et le changement rapide seront sans doute les seules composantes que l'on connaît aujourd'huiet qui seront inchangées dans dix ans. D'une façon ou d'une autre, les Américains continueront de voyager en masse et de dépenser des milliards pour les voyages. L'avenir sera à ceux qui arriveront à suivre l'évolution de ce marché et à capitaliser à partir de cet énorme potentiel. f

\begin{tabular}{l}
\hline À LA MÉMOIRE \\
DE SERGE BARTHELET \\
Décédé accidentellement le 21 juin 1990, \\
Serge était un étudiant dontl'implication \\
à l'Université et au Module de gestion et \\
intervention touristiques était totale. \\
Membre de plusieurs comités, trè's actif à \\
l'Association étudiante du Module dont \\
il fut l'un des présidents, Serge était au \\
service de l'ensemble de la communauté \\
universitaire. Le Comité de rédaction de \\
Téoros offre ses condoléances à ses pa- \\
rents et à tous ses collègues et amis(es). \\
Nous le regretterons tous. \\
Marcel Samson \\
Rédacteur en chef et \\
Directeur du Module de gestion et \\
intervention touristiques
\end{tabular}

\section{Nouveau Directeur à Téoros}

À compter du présent numéro, monsieur Louis Jolin devient lenouveau directeur de la revue. Le Comité de rédaction tient à remercier monsieur Jean Stafford pour l'excellent travail qu'il a accompli durant les trois demières années.

Marcel Samson Rédacteur en chef 